\title{
Biodiversity is key for more variety for better society
}

\section{Keywords: biodiversity; LUCA; marine biodiversity}

\section{Introduction}

As Biodiversity International Journal celebrates its first anniversary, we look back on a great year for biologists. In the past few months, we have witnessed a steady expansion of academic departments, institutes, scientific societies and journals, all geared toward the promotion of biology in biodiversity.

We study in chief the variety of life in the world or in a particular habitat or ecosystem including biodiversity typically measures variation at genetic, the species, and the ecosystem level. It can be studied on many levels. At the highest level, you can look at all the different species on the entire earth. On a much smaller scale, you can study biodiversity within a pond ecosystem or neighbouring park. Identifying and understanding the relationships between all the lives on earth are some of the greatest challenges in science. Most people recognise biodiversity by species. A species is a group of living organisms that can interbreed. Examples of species include blue whales, white - tailed deer, white pine trees, sunflowers and microscopic bacteria that you cannot even see with your eyes. Biodiversity include the full range of species that live in an area.

\section{Biodiversity at a glance}

Let's look at the species biodiversity within a local pond. At first glance, we can identify plants, including cattails and water lilies. If we wait awhile, we might be able to spot a garter snake, a bullfrog or maybe a red-winged blackbird. With a closer look, you can see invertebrates and worms under leaves, on grasses and in the pond water. Think you're done? - You have not even scratched the surface of the biodiversity within the pond! Using a microscope, you would be able to see hundreds or even thousands of different bacteria that inhibit the pond water. They are all part of the species biodiversity of this small ecosystem!

\section{Biodiversity is more than just species}

Species diversity is only one part of biodiversity. To properly catalogue all the life on earth, we also have to recognise the genetic diversity that exists within species as well as the diversity of entire habitats and ecosystems. Genetic Biodiversity is the variation in genes that exists within a species. A helpful way to understand genetic diversity is to think about dogs. All dogs are part of the same species, but their genes can dictate whether they are Chihuahua or a Great Dane. There can be a lot of variation in genes - just think about all the colours, sizes, and shapes that make up the genetic diversity of dogs. Ecological Biodiversity is the diversity of ecosystems, natural communities and habitats. In essence, it is the variety of ways that species interact with each other and their environment. The forests of Maine differ from the forests of Colorado by the types of species found in ecosystems, as well as the temperature and rainfall. These two seemingly similar ecosystems have a lot differences that makes them both special.

\section{Some biodiversity facts}

Researchers have estimated that there are between 3-30million
Volume I Issue I - 2017

\author{
Loai Aljerf \\ Department of Life Sciences, Damascus University, Syria
}

Correspondence: Loai Aljerf, Department of Life Sciences, Damascus University, Faculty of Dentistry, Damascus, Syria, Tel +963-944-482203, Email envirochrom@hotmail.com

Received: June 24, 2017 | Published: June 29, 2017

species on earth, with a few studies predicting that there may be over 100 million species on earth! Currently, we have identified only 1.7 million species, so we have a long way to go before we can come close to figuring out how many species are on earth! There is more biodiversity within tropical ecosystems than temperate or boreal ecosystems. Tropical rainforests have the most diversity. The most diverse group of animals is invertebrates. Invertebrates are animals without backbones, including insects, crustaceans, sponges, scorpions and many other kinds of organisms. Over half of all the animals already identified are invertebrates. Beetles are some of the most numerous species. Science has so much more to learn about the biodiversity of microscopic organisms like bacteria and protozoa.

\section{The importance of biodiversity}

Biodiversity is extremely important and the health of ecosystems. A few of the reasons are: (1) Biodiversity allows us to live healthy and happy lives. It provides us with an array of foods and materials and it contributes to the economy. Without a diversity of pollinators, plants, and soils, our supermarkets would have a lot less produce. Most medical discoveries to cure disease and lengthen life spans were made because of research into plant and animal biology and genetics. Every time a species goes extinct or genetic diversity is lost, we will never know whether research would have given us a new vaccine or drug. Biodiversity is an important part of ecological services that make life liveable on earth. They include everything from cleaning water and absorbing chemicals, which wetlands do, to providing oxygen for us to breathe - one of the many things that plants do for people. Biodiversity allows for ecosystems to adjust to disturbances like extreme fires and floods. If a reptile species goes extinct, a forest with 20 other reptiles is likely to adapt better than another forest with only one reptile. Genetic diversity prevents diseases and helps species adjust to changes in their environment. Simply for the wonder of it all, there are few things as beautiful and inspiring as the diversity of life that exists on earth.

\section{Threats to biodiversity}

Extinction is a natural part of life on earth. Over the history of the planet most of the species that ever existed, evolved and then gradually went extinct. Species go extinct because of natural shifts in the environment that take place over long periods of time, such 
as ice ages. Today, species are going extinct at an accelerated and dangerous rate, because of non-natural environmental changes caused by human activities. Some of the activities have direct effects on species and ecosystems, such as: (1) Habitat loss/degradation, (2) Over exploitation (such as overfishing), and (3) Spread of Nonnative Species/Diseases. Some human activities have indirect but wide-reaching effects on biodiversity, including: Climate change and Pollution. All of these threats have put a serious train on the diversity on earth. According to the International Union for Conservation of Nature (IUCN), globally about one third of all known species are threatened with extinction. That includes $29 \%$ of all amphibians, $21 \%$ of all mammals and $12 \%$ of all birds. If we do not stop the threats to biodiversity, we could be facing another mass extinction with dire consequences to the environment and human health and livelihood.

\section{Helping biodiversity in your own backyard}

You can play a part in protecting the biodiversity of your local community by creating a Certified Wildlife Habitat. One of the greatest threats to biodiversity is habit loss. A certified Wildlife Habitat provides food, shelter, water and a place to raise young for native wildlife - the essential elements of habitat that wildlife need to survive. A Certified Wildlife Habitat can provide food and homes for a range of local species that need your help.

\section{Biodiversity types}

Terrestrial biodiversity tends to be greater near the equator, which seems to be the result of the warm climate and high primary productivity. Biodiversity is not distributed evenly on Earth, and is richest in the tropics. These tropical forest ecosystems cover less than 10 per cent of earth's surface, and contain about 90 percent of the world's species. Marine biodiversity tends to be highest along coasts in the Western Pacific, where sea surface temperature is highest and in the mid-latitudinal band in all oceans. There are latitudinal gradients in species diversity. Biodiversity generally tends to cluster in hotspots, and has been increasing through time, but will be likely to slow in the future. Rapid environmental changes typically cause mass extinctions. More than 99.9 percent of all species that ever lived on Earth, amounting to over five billion species, are estimated to be extinct. Estimates on the number of Earth's current species range from 10 million to 14 million, of which about 1.2 million have been documented and over 86 percent have not yet been described. More recently, in May 2016, scientists reported that 1 trillion species are estimated to be on Earth currently with only one-thousandth of one percent described. More recently, in May 2016, scientists reported that 1 trillion species are estimated to be on Earth currently with only one-thousandth of one percent described.

The total amount of related DNA base pairs on Earth is estimated at $5.0 \times 10^{37}$ and weighs 50billion tonnes. In comparison, the total mass of the biosphere has been estimated to be as much as $4 \mathrm{TtC}$ (trillion tons of carbon). In July 2016, scientists reported identifying a set of 355 genes from the Last Universal Common Ancestor (LUCA) of all organisms living on Earth. The age of the Earth is about 4.54 billion years. The earliest undisputed evidence of life on Earth dates at least from 3.5billion years ago, during the Eoarchean Era after a geological crust started to solidify following the earlier molten Hadean Eon. There are microbial mat fossils found in 3.48billion-year-old sandstone discovered in Western Australia. Other early physical evidence of a biogenic substance is graphite in 3.7billion-year-old meta-sedimentary rocks discovered in Western Greenland. More recently, in 2015, "remains of biotic life" were found in 4.1 billion-year-old rocks in Western Australia. According to one of the researchers, "If life arose relatively quickly on earth, then it could be common in the universe."
Since life began on Earth, five major mass extinctions and several minor events have led to large and sudden drops in biodiversity. The Phanerozoiceon (the last 540 million years) marked a rapid growth in biodiversity via the Cambrian explosion-a period during which the majority of multicellular phyla first appeared. The next 400 million years included repeated, massive biodiversity losses classified as mass extinction events. In the Carboniferous, rainforest collapse led to a great loss of plant and animal life. The Permian-Triassic extinction event, 251 million years ago, was the worst; vertebrate recovery took 30. The most recent, the Cretaceous-Palaeogene extinction event occurred 65 million years ago and has often attracted more attention than others because it resulted in the extinction of the dinosaurs. The period since the emergence of humans has displayed an ongoing biodiversity reduction and an accompanying loss of genetic diversity. Named the Holocene extinction, the reduction is caused primarily by human impacts, particularly habitat destruction. Conversely, biodiversity positively impacts human health in a number of ways, although few negative effects are studied. The United Nations designated 2011-2020 as the United Nations Decade on Biodiversity. Thus, it is time to remind that biodiversity worth more than gold and is the way, so we should not let nature goes astray. In addition, each of us is responsible for everything to everyone else.

\section{Editorial}

In fact, we have been thrilled to be a part of this remarkable period in the evolution and vitalization of the field. We launched Biodiversity International Journal with the goals of publishing the highest-calibre research and commentary at the interface of chemistry and biology, raising the international visibility of the field and fostering the development of a broader community of chemists and biologists. Although this community will be the ultimate judge of our success as a journal, we are gratified by the positive feedback that we have received thus far. We are grateful to our authors, who chanced a contribution to a budding journal, our referees, who volunteered their valuable time, and our readers, who continue to read each issue from cover to cover. Even though the term 'Biodiversity' has existed for over a decade, it continues to mean different things to different people. To some, the term is simply puzzling. But most scientists know Biodiversity when they see it. Since Biodiversity's inception, the editorial team has viewed biology in the broadest possible terms. We have endeavoured to connect with the field's roots in bioorganic chemistry and capture the importance of chemical tools and small molecules for understanding biological systems. Yet we have sought to have our pages reflect a defining characteristic of most chemical biologists: a willingness to adopt ideas and techniques from across all areas of chemistry and biology and to apply them to understand or manipulate biological systems at the molecular level. We share the view of one of our early authors that chemical biology cannot exist without the biology", and so we have emphasized new biological insights as an important priority for the field and our journal. Our editorial scope has been organized around four thematic areas of chemical biology research:

I. Chemical synthesis: investigating bond-breaking and bond-making processes that drive metabolism in cells and enable the development of chemical tools.

II. Chemical mechanisms in biology: understanding the molecular mechanisms of natural biological systems using chemical and biological techniques.

III. Expanding biology through chemistry: applying small molecules, chemical tools and engineered biomolecules to broaden the scope of biological processes. 
IV. Expanding chemistry through biology: taking inspiration from biology to discover and develop new frontiers in chemistry.

To mark our anniversary, the editorial team has compiled some highlights of our first year that we feel represent our editorial scope and the diversity of content featured in Biodiversity International Journal. The next content index illustrates a breadth of original research at the interface of chemistry and biology. Several kinds of papers demonstrate the utility of combining computational and experimental approaches: as for instance, this combined approach is used to understand protein aggregation mechanisms and the use to identify off-target effects of known drugs. Chemical tools for protein labelling and the screening of membrane-protein libraries can be intermingled with new mechanistic insights into enzymatic catalysis and the cellular effects of small aromatic compounds. The original research contributions have enhanced online content. We hope pleased to become the first scientific journal to feature an online index of the chemical compounds that are described in each paper and to include in the future links to the structures deposited in the Pub Chem database of the US National Library of Medicine. Our anniversary issue also includes highlights of several frontier areas of chemical biology. In the next issue, we feature a Review article on synthetic biology that discusses the challenges facing chemists and biologists who seek to engineer new function into living systems, a meeting report will be designed to cover advances in chemical genetics and drug discovery and a commentary examining the importance of carbon-nitrogen bonds in chemistry and biology. We are also pleased to welcome the addition of other types of articles, called 'Elements', to the pages of Biodiversity International Journal. Elements, which will appear regularly in print and online, will feature interviews with key people in the sustainability and chemical biology community and offer insights into places or events that are of general interest to chemists and biologists. We welcome your ideas for people, places and events to feature in upcoming Elements. As we embark on our first year, we will start our efforts to deliver the best of Biodiversity International Journal research and commentary. In the coming year, readers can look forward to the expansion of Biodiversity International Journal, including thematic issues and enhanced involvement with the community. Thanks for sharing our enthusiasm for chemical biology and reading Biodiversity International Journal.

\section{Acknowledgements}

It has been and still a real pleasure and certainly a rewarding experience serving as Associate Editor of Biodiversity International Journal and I will do my best to face all challenges that confront the journal, striving to increase the quality and impact of the journal's content. Editorial obligations have not been a simple task and it is a time consuming, and I have been enjoyed and benefited from all the published articles in this esteem journal. Furthermore, I would like to thank and express my sincere gratitude to the publisher, technical staff and the Editorial Board of Biodiversity International Journal for their assistance and providing support and feedback necessary to develop and publish this material of such consistent of high quality. As a result, it is my pleasure to invite all researchers in biodiversity and environmental science to submit their scientific articles to Biodiversity International Journal.

\section{Conflict of interest}

Author declares there is no conflict of interest in publishing the article.

\section{References}

1. Nole A, Talbert T. Qualitative assertions as prescriptive statements. Educational Psychology Review. 2011;23(2):263-271.

2. Al-Akiti MA. Index to divisions of al-Ghazālī's often-cited published works. The Muslim World. 2011;102(1):70-200.

3. Zafar F, Khan A, Ahmed M, et al. A scalable data integrity mechanism based on provable data possession and Khan JARs. KSII Transactions on Internet and Information Systems. 2016;10(6)2851-2873.

4. Kritchevsky SB, Knight BG. Preparing your work for publication: tips from the editors. The Gerontologist. 2015;55(2):304.

5. Princy B, Joseph NE. Securing and low time consuming for sharing high sensitive and relevant data. International Journal of Science and Research. 2016;5(6):2165-2166.

6. Miller J, Georgiev T, Stoev P, et al. Corrected data re-harvested: curating literature in the era of networked biodiversity informatics. Biodiversity Data Journal. 2015;3:e4552.

7. Gougousis A, Bailly N. Life Watch Greece Portal development: architecture, implementation and challenges for a biodiversity research e-infrastructure. Biodiversity Data Journal. 2016;4:e9434.

8. Zhang J. Biodiversity science and macro ecology in the era of big data. Biodiversity Science. 2017;25(4):355-363. 